\title{
FOTOGRAFIA, CIÊNCIA E MITO Uma interseção estética
}

\begin{abstract}
Ana Taís Portanova Barros ${ }^{1}$
Resumo: Passados mais de 170 anos de sua descoberta, a fotografia ainda assombra ciência e senso comum por sua testemunhabilidade, acenando para uma estética profundamente enraizada no tempo vivido. A ciência e, nesse caso especial, a semiologia, vocacionada à desmitologização, fez da fotografia objeto de estudo sob a égide de sua ontologia sígnica em geral, indicial em particular. Paradoxalmente, as tentativas científicas de separar representação de realidade fazem supor o absoluto da realidade fotográfica, retornando ao tempo total do mito, remitologizando o que se queria desmitologizado. Em vez de indicar um erro no procedimento científico, essa recursividade sinaliza a imperatividade da experiência e a presença do illud tempus mesmo no mais racional dos empreendimentos humanos.
\end{abstract}

Palavras-chave: Fotografia. Ciência. Mito.

\begin{abstract}
After 170 years of its emergence, photography still astounds science and common sense for its "witnessability", hinting at some aesthetics that is deeply rooted in the time that has been lived. Science - and more specifically semiology, which is concerned with demythologizing - has turned photography into an object of study that lies under the aegis of its ontology: signic in general terms, indexical in particular terms. Paradoxically, the scientific attempts to dissociate representation from reality have us assume the absolute in the photographic reality, returning to the total time of the myth, remythologizing what should be demythologized. Instead of an error in the scientific procedure, such recursion suggests the paramount importance of the experience and the presence of illud tempus even in the most rational of human endeavors.
\end{abstract}

Keywords: Photography. Science. Myth.

\section{Construção dogmática na Fotografia}

As reflexões sobre a fotografia, desde seu nascimento, parecem esbarrar em dificuldades relacionadas à falta de autonomia disciplinar. Sem saber se é técnica ou arte, a fotografia seguiu pelo século XX procurando legitimações numa e noutra área separadamente. Se, além e/ou aquém da técnica e da arte, considerarmos a fotografia como um campo de conhecimento e a olharmos sob a lente do sociólogo português Boaventura de Souza Santos

\footnotetext{
${ }^{1}$ Professora do departamento de Comunicação da UFRGS, área de Fotografia. Doutora em Ciências da Comunicação pela ECA/USP.
} 
(1989), perceberemos que já temos elementos capazes de situá-la em termos de produção científica porque ela, apesar de largamente praticada por amadores, sempre tentou se separar do senso comum. Esta separação, segundo Santos (1989: p.18), é crucial para a produção científica num primeiro estágio, aquele por ele chamado de construção dogmática. O segundo estágio seria o da desconstrução ou desdogmatização, hoje conhecido como crise de paradigmas. A dogmatização corresponde à crise de crescimento; a desdogmatização, à crise de degenerescência. Na crise de crescimento, o discurso científico se separa do senso comum, do discurso artístico, do discurso religioso e do mítico. É a primeira ruptura epistemológica. $\mathrm{Na}$ crise de degenerescência, as conseqüências sociais e humanas da ciência pedem à consciência científica uma retomada do diálogo com o saber comum e com os demais saberes.

Para dirimir alguma dúvida sobre o fato de a fotografia pretender se estabelecer como ciência ou, pelo menos, como campo de conhecimento, citamos a multiplicação de cursos de graduação e pós-graduação em fotografia e o surgimento de periódicos científicos especializados em fotografia. Não se trata, agora, de discutir o que é ciência e sim de constatar, por assim dizer, uma vontade de ciência. Destarte, podemos retomar Santos e pensar, com ele, que o paradigma da ciência moderna, da crise de crescimento da ciência se constituiu contra o senso comum, recusando-se a se orientar para a vida prática. O único conhecimento válido seria o científico, por causa da objetividade; e a objetividade é alcançada através da separação entre teoria e prática, ciência e ética. De modo não mais do que ligeiro, podemos verificar essa verdade também para a fotografia, sendo facilmente constatável que os grandes fotógrafos não são pensadores da fotografia e os grandes pensadores da fotografia não são grandes fotógrafos. O ensaísta inglês Geoff Dyer (2008: p. 18) chega mesmo a afirmar que não saber fazer fotos é condição para se falar de fotografia. (Ele assevera que nem mesmo possui uma câmera fotográfica.)

Examinando o percurso das reflexões que tomam a fotografia como objeto, se vê que sua autonomia disciplinar parece ser buscada repetidas vezes por meio de uma definição ontológica, algo capaz de estabelecer um ponto em comum entre todas as fotografias e que, uma vez encontrado, a um só tempo permitiu o avanço da tomada da fotografia como objeto científico e a ruptura com o senso comum sobre a fotografia. No final da década de 1950, Barthes publica seu Mitologias e, na década de 1960, A mensagem fotográfica. No segundo texto (1969), Barthes estabelece balizas para a verificação do que havia afirmado no primeiro (1999) sobre o caráter sígnico da fotografia. Parece que desde então este caráter não foi mais questionado; afinal, a fotografia seria sempre a representação de algo, significando sempre para alguém. Sem grandes polêmicas a respeito deste fundamento, a discussão maior se 
estabeleceu a partir da relação da fotografia com o referente - se indicial, icônica ou simbólica. Mesmo hoje, muitos estudos sobre a fotografia têm sua ontologia sígnica como autoevidente, o que reservaria a leitura da imagem fotográfica à semiologia.

\section{Desmitologização e remitologização através do índice}

Estabilizada a ideia da fotografia como sistema de signos, chegou-se à anterioridade e supremacia do caráter indicial da fotografia, nos termos de Peirce, sobre seu possível caráter simbólico ou icônico. No entanto, esta ideia, sustentada durante muito tempo e por alguns dos mais citados estudiosos sobre o tema (KRAUSS, 2002; DUBOIS, 1993; SCHAEFFER, 1996) tem sido aos poucos desacreditada, como veremos adiante. Por outro lado, mesmo quando se passa ao largo da discussão sobre o pertencimento da fotografia ao reino do índice, símbolo ou ícone, deixa-se vazar a pulsão fotográfica da foto-índice. O apelo de interesse da fotografia vem da experiência física que a foto como índice supõe. Precisamente neste ponto é que acontece a formação da imagem, e agora não estamos falando do ícone, índice ou símbolo fotográfico, e sim da imagem como produto principal da imaginação, aquela que resulta da junção do ver (a fotografia em si) com o viver. Ou seja, nestes termos, a imagem não está na fotografia e fotografia não é imagem.

A fotografia faz uma afirmação de existência que convoca nossas experiências pessoais e dá origem à imagem. A afirmação de existência que a foto-índice faz importa não por ser verdadeira, mas por se acreditar nela. Pensar a fotografia a partir da inquestionabilidade de seu referente - ou seja, do seu caráter sígnico -, paradoxalmente é muito mais um procedimento próprio ao pensamento mítico do que ao científico. O mito, já nos ensinou Eliade (1994), narra a fundação das coisas, sendo profundamente calcado numa verdade primeira à qual sempre podemos retornar porque ela está sempre dentro do homem. Todos e somente os mitos são verdadeiros; eles sempre falam de realidades absolutas. Se a fotografia for entendida como se referindo a alguma coisa que existe indiscutivelmente, podemos dizer que ela está sendo tratada como um mito porque, nesse caso, a afirmação de existência feita pela fotografia é a mesma que o mito faz.

Já em 1844, Talbot (2007), ao publicar seu livro O lápis da natureza, ressaltava que na fotografia a própria natureza se retratava a si mesma. Passado um século, em 1945, André Bazin (apud MACHADO, 2005), em Ontologia da Imagem Fotográfica, dizia o mesmo de outra forma, com o conceito de gênese automática, segundo o qual a fotografia registra mecanicamente o mundo, sem a intervenção direta do homem. Notemos como essas ideias 
iniciais supõem a fotografia como índice, ligada fisicamente ao que representa, sendo mesmo um gesto material do seu referente e constituindo, então, prova da existência desse referente.

O correr dos anos não modifica a ideia da fotografia como signo e, mais especificamente, como signo indicial. Dubois lançou em 1983 sua obra $O$ ato fotográfico e Schaeffer, em 1987, A imagem precária. Ambos reafirmam a natureza indicial da fotografia. Dubois (1993) explicita que a fotografia, como o índice, resulta de uma conexão física com o objeto retratado, já que os raios luminosos que tocam esse objeto são os mesmos que sensibilizam a película. Segundo o autor belga, a fotografia partilha com os signos indiciais as características de singularidade (o que a fotografia reproduz ao infinito aconteceu só uma vez), atestação (por sua gênese, a fotografia testemunha) e designação (a fotografia aponta com o dedo, "ali", mas nada afirma). Embora Dubois coloque limites à referencialidade da fotografia, circunscrevendo-a ao momento do clique, permanece a conviç̧ão de que uma fotografia é sempre a imagem de alguma coisa que está no mundo.

Parece, assim, que, desde seu surgimento, a fotografia é considerada um rastro incontornável da realidade, tão capaz de atestar a existência de algo quanto um fragmento material do objeto em questão. A essa visão se contrapõe a de estudiosos como Machado (2001), segundo o qual a fotografia raramente é um índice; pode até ser um ícone e sempre é símbolo. Isso se diferencia claramente da argumentação de Dubois, para quem a fotografia é antes índice e nunca ícone, já que o ícone não implica a existência do referente. Ou seja, a experiência referencial da fotografia é o ato que a funda (DUBOIS, 1993: p. 53). No entanto, Machado sustenta que os raios luminosos que sensibilizam a película não caracterizam uma conexão física do signo com seu referente a menos que tudo no universo seja também considerado índice, já que tudo, de alguma maneira, sofre a ação da luz. Para esse autor brasileiro, a fotografia é índice somente no caso dos fotogramas produzidos por contato direto entre o objeto retratado e o papel sensibilizado. Nos demais casos, a fotografia pode até ser um ícone, se guardar uma semelhança com o referente, e sempre será um símbolo, posto que sempre é uma interpretação físico-química do referente operada pelo equipamento, pela película, pelo processo de revelação.

[...] a película fotográfica só pode responder à paisagem focalizada com a gama de cores que ela é capaz de produzir. A quantidade de verdes que se pode encontrar na natureza é possivelmente infinita, porque infinitos são os corpos físicos com suas diferentes propriedades reflexivas, mas um determinado padrão fotográfico [...] produz uma gama de verdes não apenas finita, como também padronizada, regular e fixa (MACHADO, 2001: p. 124). 
Machado, corroborando o pensamento de Flusser (2002), para quem a fotografia traduz teorias científicas em imagens, afirma, assim, que a fotografia é

[...] antes de qualquer outra coisa, o resultado da aplicação técnica de conceitos científicos acumulados ao longo de pelo menos cinco séculos de pesquisas nos campos da ótica, da mecânica e da química, bem como também da evolução do cálculo matemático e do instrumental para operacionalizá-lo (MACHADO, 2001: p. 129).

E conclui: “A verdadeira função do aparato fotográfico não é, portanto, registrar um traço, mas interpretá-lo cientificamente" (2001: p. 129).

\section{Fotografia sem referente}

A liberação da fotografia de seu referente só começa a ser aceita recentemente por alguns autores que, no rastro de Fontcuberta (2007), falam na desindexação da fotografia por causa da sua digitalização:

La fotografía há sufrido en la era electrónica un proceso de desindexilización. El nuevo elscenario devuelve a la imagen la linealidad de la escritura. La fotografía se libera de la memoria, el objeto se ausenta, el índice se desvanece. Todo ello aboca a la fotografía a un nuevo estádio epistemológico: la cuestión de representar la realidad deja paso a la construcción del sentido (FONTCUBERTA, 2007: p. 12).

Ora, se a fotografia feita com suporte sensível à luz é considerada índice, não há por que considerar a fotografia digital diferente, posto que é ainda a luz que, uma vez atingindo o sensor da máquina fotográfica, fá-lo carregar-se eletricamente. O sensor é na verdade um chip que contém um conjunto de díodos de silício fotossensíveis. Cada um dos díodos acumula uma carga elétrica de acordo com a quantidade de luz que o atinge, carga essa que vai ser processada e apresentada como pixel do mesmo modo que cada grão de prata da película atingido pela luz vai se transformar em prata metálica após o processo de revelação.

O fato é que a fotografia digital chamou a atenção para o grande potencial de manipulação de que é dotada a imagem fotográfica. Esse potencial acompanha a fotografia desde seu nascimento, mas a digitalização faz com que essa manipulação possa ser imperceptível e esteja ao alcance de qualquer um. Ao se falar na desindexação da fotografia advinda com a sua digitalização, novamente o raciocínio não parece se fundar em uma verdade científica, e sim em uma sensação de perda de materialidade, sensação esta que igualmente indica uma estética.

A consciência de que "todas as imagens são embustes" (DEBRAY, 1993: p. 264) parece finalmente chegar ao senso comum sem que o fascínio pela fotografia diminua. As 
câmeras são cada vez menores, mais leves e com maior qualidade de imagem, embutidas em telefones celulares e computadores portáteis, sempre disponíveis para um clique em meio à correria do cotidiano. Para acolher o inestimável número de fotografias produzidas todos os dias, sites especializados oferecem serviços de armazenamento e exibição, gratuitos para quem é mais moderado em sua produção, pagos para quem deseja depositar um número maior de fotografias.

A fotografia, nascida na modernidade, viu surgir o cinema, a televisão, o videotape, a imagem digital e chega à pós-modernidade perfeitamente integrada às novas estéticas: é assumida em sua impessoalidade, em seu hibridismo, em sua recusa à originalidade. Entler mapeia três formas de manifestação da fotografia que têm tido

[...] forte penetração nos espaços que se definem como voltados à arte contemporânea: a) um documentarismo constituído de poses simples e registros frontais, sem apelos retóricos ou, eventualmente, apoiado em modelos bastante assimilados pela tradição da fotografia; b) o resgate de uma plasticidade vulgar ligada a temáticas e objetos considerados pelo senso comum como "estéticos", como a natureza, a paisagem urbana e o corpo; c) o recurso a procedimentos técnicos pouco elaborados, às vezes levianos, numa aproximação à fotografia amadora (ENTLER, 2008: p. 9-10).

A fotografia passou por momentos em que ser arte significava sua salvação e por isso tentou copiar a pintura; quase ao mesmo tempo, outro movimento na fotografia seria no sentido de negar-se a copiar a pintura e ir até os limites da técnica genuinamente fotográfica, assumindo suas características todas, constituindo sua própria arte. Chega-se hoje a um momento em que a fotografia, enquanto prática, não se sente no dever de prestar contas a ninguém, como podemos verificar nas manifestações detectadas acima por Entler. O interesse geral pela fotografia se conservou intacto, não obstante as turbulências identitárias e conceituais por que tem passado. Seja ela praticada com técnicas fortemente elaboradas ou com a simplicidade do "aperte o botão e nós fazemos o resto",2, há algo que se mantém constante na fotografia ao longo do tempo. Donde provém esse enlevo? Será que seria de seu suposto caráter sígnico, ou seja, do fato de representar alguma coisa para alguém?

Retomamos a idéia anteriormente explicitada da fotografia como imagem mítica e postulamos que não é a potencialidade de representação e sim de apresentação e até de abdução a responsável por esse fascínio. Quando se está diante de uma fotografia, é-se introduzido em uma realidade inteira. Uma apresentação com imediata imersão, diferente,

\footnotetext{
${ }^{2}$ Esta frase era o bordão da campanha publicitária da primeira máquina fotográfica construída especificamente para o público amador, a Kodak, em 1888, por George Eastman. A nova câmera permitiu que milhões de pessoas pudessem fazer fotografias, prática antes cara e complicada, reservada aos profissionais.
} 
pois, da apresentação de que Barthes (1969: p. 302) falava ao definir a fotografia como "mensagem sem código", ou seja, o "analogon perfeito". O semiólogo estabelecia, no entanto, uma distinção: a mensagem sem código só o era para o senso comum. Na verdade, essa aparente não codificação, que não exigiria, portanto, um esforço para se compreender o significado da fotografia, serviria não mais do que como um álibi para a outra mensagem, aquela que contém a retórica fotográfica e, sim, é fortemente codificada, eivada de processos de conotação. Assim, a apresentação de que Barthes fala não seria mais do que um acobertamento da verdadeira natureza da fotografia, que é de representação.

Representações supõem sempre uma realidade outra que não aquela que está à frente do sujeito. Essa realidade em si se manteria intacta enquanto sobre ela se constroem, à vontade, representações. Ora, uma representação tal como a efetuada pelo signo, também chamado por Peirce (1984) de representamen, é uma conexão entre dois elementos: o objeto por um lado e a idéia na mente da pessoa por outro. Fala-se então de um processo de imaginação racional - porque raciocinar é um jeito de imaginar. No entanto, o encadeamento lógico de pensamentos, o processo discursivo que produz e expressa esses pensamentos e que define o raciocínio não parece corresponder ao verdadeiro rapto que a imagem fotográfica em geral é capaz de promover no sujeito. Diante de uma fotografia, não é comum que o espectador se detenha a raciocinar, a filosofar; ou é invadido pelo pathos, entregando-se à experiência estética, ou então permanece indiferente.

\section{Tempo primordial}

Wunenburger, ao falar do surgimento da categoria do sublime em Kant, assim contextualiza o pahtos:

\footnotetext{
Enquanto o belo reenvia a formas finitas, dotadas de propriedades intrinsecamente agradáveis ao gosto, o sublime designa o pathos que invade o sujeito assim que ele é tocado por formas ou forças infinitas, que excedem toda representação finita. Por esta experiência o espírito humano se encontra diante de um irrepresentável que confronta a razão com a transcendência que a ultrapassa e torna sensível (perceptível) sua finitude diante do absoluto. É assim que Kant abre no sublime um espaço para o pensamento simbólico, que busca, através de um modo não conceitual, satisfazer as aspirações da incondicionalidade da razão humana (WUNENBURGER, 1998: p. 80, tradução nossa).
}

Tal invasão pelo pathos sinaliza, pois, o pensamento simbólico, ou seja, o pensamento por imagens simbólicas. Trata-se de um atalho que atinge o conhecimento de seu objeto sem 
utilizar os longos percursos do raciocínio. Ao dizermos pensamento simbólico não nos referimos ao símbolo da teoria dos signos, que junta arbitrariamente duas coisas, constituindo talvez o mais racional dos signos. Falamos, isto sim, do símbolo dos estudos do imaginário, aquele levantado por Durand (1997), que não se subordina ao signo, sendo muito mais uma espécie de emanação do referente, fusão entre uma imagem mental e um sentido vivido. A reivindicação que os estudos do imaginário fazem de um pensamento por imagens (simbólicas no sentido que acabamos de descrever) já estava autorizada pela filosofia pelo menos desde o século 18, quando Kant (1790 apud WUNENBURGER, 1998) chamou a atenção para a categoria do sublime, à qual a própria razão se rende quando se descobre incapaz de representar o mundo do pathos, como citamos acima.

A necessidade do pensamento simbólico aparece na própria obra de Barthes. Na fase inicial de seu trabalho, Barthes (1999) dizia que a fotografia deve ser dissecada semiologicamente, deve ser desmascarada pelo estudioso, que trará à luz o que o autor chamava de significante pleno, ou seja, resultante da separação entre sentido e forma, de modo a se perceber a deformação que um causa no outro. Ora, vinte anos mais tarde o sistema de análise de fotografias que construiu ciosamente não lhe trazia respostas satisfatórias. Como bem observa Etienne Samain (1998), o homem de A mensagem fotográfica (1969) não é o mesmo de A câmara clara (1984), o que fala do studium, designando o registro feito pela câmara, e do punctum, tentando cercear o indefinível, agarrar o impalpável, aquilo de que a foto não fala. Sobre a organização dos retratos de sua mãe, após a morte dela, disse Barthes: "Eu lia minha inexistência nas roupas que minha mãe tinha usado antes que eu pudesse me lembrar dela" (BARTHES, 1984: p. 97). Ao olhar os retratos da mãe morta, Barthes não conseguiu separar sentido e forma e chegar ao significante pleno. O enquadramento da fotografia como um signo decodificável passa bem longe do punctum, esse sentido obtuso que

[...] não pertence mais ao domínio da língua, mas que se confessa na abertura de uma ferida. É a ausência e o silêncio de todo sentido que, paradoxalmente, provoca um novo sentido, este grito, íntimo, intenso, necessário a seres vivos, confrontados naquilo de que sempre a fotografia fala: a vida e a morte, o tempo e a existência (SAMAIN, 1998: p. 125).

A fotografia é uma imagem mítica, e não sígnica. Ao dizermos mito, não estamos falando de falseamento da realidade ou de naturalização da história, como Barthes acusava no seu Mitologias (1999), em 1957. Usamos a palavra mito na acepção respeitosa e reverente de estudiosos do imaginário como Eliade (1992) e Durand (1997), para os quais mito é não só uma narrativa exemplar, mas também um caminho que nos joga diretamente nos braços do 
illud tempus, o tempo primordial em que todas as coisas são criadas e que acolhe, portanto, todas as possibilidades de que o sujeito precisa para se autorrealizar. O tempo mítico não é um tempo no qual possamos ingressar usando o raciocínio ou as representações porque ele é, acima de tudo, experiência. No pensamento sobre a fotografia, na recepção de fotografias, o pensamento mítico força passagem e encontra uma brecha na estrutura lógica construída pela teoria dos signos, fluindo através do caráter de experiência que o signo indicial supõe. Daí a sobrevivência da ideia de índice na fotografia, por mais que a imaginação racional possa atestar o contrário. Aliás, Durand (1997) adverte que o imaginário não é sensível à lógica, e é isso que explica, por exemplo, certos temores bem reais que cultivamos em relação a coisas inofensivas.

Existe uma familiaridade nas imagens fotográficas, senão em todas, pelo menos nas que se aproximam do estilo figurativo. Essa familiaridade com cenas que já vimos, com mundos que nos parecem conhecidos, mas que em verdade são construídos no momento mesmo em que entramos em contato com a fotografia conferem a ela poderes demiurgicos, de criação. Se não é possível constatá-los em si, é possível ver seus efeitos: assim como a urbanidade mutante do final do século XIX levou fotógrafos documentaristas de então a registrarem abundantemente as cidades antigas que desapareciam cedendo lugar para as modernas instalações de água, esgoto, eletricidade, gás e para construções que superaproveitaram o espaço disponível, assim também os fotógrafos contemporâneos se lançam a registrar um mundo em via de desaparecimento. As imagens são tão mais abundantes quanto maior é o temor profundo pela liquidação desse mundo e tão mais manipuladas quanto maior é o desejo de construção de um outro mundo.

\section{Eficácia da imagem}

Assim, paradoxalmente, partindo de uma teoria que postula o caráter sígnico e, pois, representativo da fotografia, chegamos à possibilidade de que esse caráter representativo não passe de uma vestimenta civilizada que fornecemos para uma entidade primitiva e incontornável: o mito. Senão, vejamos: mesmo com todos os argumentos capazes de demonstrar que a fotografia não é signo indicial, ou seja, não é causada pelo objeto, facilmente o sujeito se trai e trata a fotografia como fragmento material daquilo que ali deveria estar longinquamente representado. Daí a olhar para a fotografia do mesmo jeito que se abre a janela de casa e se olha para o mundo não temos muita diferença. Eis a fotografia como apresentação do mundo, mesmo com todas as precauções da nossa racionalidade. A 
persistência do pensamento que situa no signo indicial a característica fundadora da fotografia é, nesse quadro, dada pela legitimação racional que esse pensamento faz à experiência mítica proporcionada pela fotografia. É por introduzir verdadeiramente o sujeito num mundo que a fotografia parece tão convincentemente um fragmento material desse mundo.

A eficácia da imagem atesta sua realidade e se torna tão mais perigosa quanto menos reconhecida. O não reconhecimento da imagem e do imaginário como vias de conhecimento do mundo flagra-se, por exemplo, na clivagem entre razão e símbolo ao se considerar racionalmente a fotografia como representação e simbolicamente (quer dizer, no nível das tripas, no nível do splacnisomai ${ }^{3}$, e não no nível do signo simbólico) como apresentação. No entanto, é diferente quando a razão compreende, como queria Kant (apud WUNENBURGER, 1998) que há instâncias em que ela é incompetente, só restando reconhecer um mundo de aporias do qual ela não tem a bússola e no qual só circulamos através do pensamento simbólico. Se não existe uma realidade em si, a verdade não é indiferente à nossa presença e tudo que está ao nosso redor é constructo, realização do imaginário. Tal consciência dissipa todo constrangimento que poderia haver quando trememos diante do retrato de nosso ancestral de bigodes e barbas longas, tão soberano que nos faz sentir medo. Essa fotografia não é, então, um simples pedaço de papel que contém um signo histórico e sim portal de imediata abdução para o tempo mítico. A outra opção é seguir na torturante experiência de separação mente-corpo, sujeito-objeto, homem-natureza, experiência-realidade. Como diz Feyerabend, é necessário um milagre para eliminar o abismo entre esses termos dicotômicos, e a criatividade deverá ser esse milagre. E não é emblemático que "a supostamente mais racional visão do mundo ainda existente só possa funcionar se combinada com os acontecimentos mais irracionais que existam, por exemplo, os milagres" (FEYERABEND, 1991: p. 166)? Ou seja, que a ciência não possa prescindir do mito?

\section{Referências bibliográficas}

BARTHES, Roland. A câmara clara: nota sobre a fotografia. Rio de Janeiro: Nova Fronteira, 1984.

A mensagem fotográfica. In: Teoria da Cultura de Massa. Org.: Luiz Costa Lima. Rio de Janeiro: Saga, 1969.

DEBRAY, Régis. Vida e morte da imagem: uma história do olhar no ocidente. Petrópolis: Vozes, 1993.

\footnotetext{
${ }^{3}$ Splacnisomai é um vocábulo aramaico, recuperado por Restrepo (1998), que designa a capacidade de, literalmente, sentir com as tripas, traduzindo, por exemplo, o dom que Cristo tinha de sentir no próprio corpo a dor que assolava os enfermos que se lhe apresentavam.
} 
DUBOIS, Philippe. O ato fotográfico. Campinas: Papirus, 1993.

DURAND, Gilbert. As estruturas antropológicas do imaginário: introdução à arquetipologia geral. São Paulo: Martins Fontes, 1997.

DYER, Geoff. $O$ instante contínuo: uma história particular da fotografia. São Paulo: Companhia das Letras, 2008.

ELIADE, Mircea. Mito e realidade. São Paulo: Perspectiva, 1994.

. Mito do eterno retorno. São Paulo: Mercuryo, 1992.

. Mitologias. Rio de Janeiro: Bertrand Editores, 1999.

ENTLER, Ronaldo. Fotografia contemporânea: entre olhares diretos e pensamentos obtusos. In: XXXII CONGRESSO BRASILEIRO DE CIÊNCIAS DA COMUNICAÇÃO, 2008, Curitiba. Anais... Intercom: Curitiba, 2008. 1 CD.

FATORELLI, Antonio. Fotografia e modernidade. In: O fotográfico. Org.: Etienne Samain. São Paulo: Hucitec, 2005. p. 81-92.

FEYERABEND, Paul Karl. Adeus à razão. Lisboa: Edições 70, 1991.

FLUSSER, Vilém. Filosofia da caixa preta. Ensaios para uma futura filosofia da fotografia. Rio de Janeiro: Relume Dumará, 2002.

FONTCUBERTA, Joan. Prólogo. In: Estética fotográfica. Org.: FONTCUBERTA, Joan. Barcelona: Editorial Gustavo Gili, 2007. p. 7-13

KRAUSS, Rosalind. O fotográfico. Barcelona: Editorial Gustavo Gili, 2002.

MACHADO, Arlindo. A fotografia como expressão do conceito In: $O$ quarto iconoclasmo $e$ outros ensaios hereges. Rio de Janeiro: Rios Ambiciosos, 2001. p. 120-138.

PEIRCE, Charles Sanders. Semiótica e filosofia. São Paulo: Cultrix, 1984.

RESTREPO, Luís Carlos. O direito à ternura. Petrópolis: Vozes, 1998.

SAMAIN, Etienne. Um retorno à câmara clara: Roland Barthes e a antropologia visual. In: $O$ fotográfico. Org.: Etienne Samain. São Paulo: Hucitec, 2005. p. 115-128.

SANTOS, Boaventura de Souza. Introdução a uma ciência pós-moderna. Rio de Janeiro: Graal, 1989.

SCHAEFFER, Jean-Marie. A imagem precária: sobre o dispositivo fotográfico. Campinas, SP: Papirus, 1996.

TALBOT, William Henry Fox. El lápiz de la naturaleza. In: Estética fotográfica. Org.: FONTCUBERTA, Joan. Barcelona: Editorial Gustavo Gili, 2007. p. 49-51.

WUNENBURGER, Jean-Jacques. Histoire des images siècle XVIII-XIX. In: Introduction aux méthodologies de l'imaginaire. Org.: Jöel Thomas. Paris: Ellipses, 1998. 